\title{
Conventional Lymphangiography (CL) in the Management of Postoperative Lymphatic Leakage (PLL): A Systematic Review
}

\section{Konventionelle Lymphangiografie (KL) beim Management postoperativer Lymphleckagen (PLL): Eine Systematische Übersicht}

Authors

Christof M. Sommer ${ }^{1}$, Claus C. Pieper ${ }^{2}$, Maxim Itkin ${ }^{3}$, Gregory J. Nadolski³ ${ }^{3}$ Saebeom Hur ${ }^{4}$, Jinoo Kim5, Geert Maleux ${ }^{6}$, Hans-Ulrich Kauczor ${ }^{1}$, Goetz M. Richter ${ }^{7}$

Affiliations

1 Clinic for Diagnostic and Interventional Radiology, University Hospital Heidelberg, Germany

2 Department of Radiology, University Hospital Bonn, Germany

3 Center for Lymphatic Imaging and Interventions, Hospital of the University of Philadelphia, Germany

4 Department of Radiology, Seoul National University Hospital, Seoul, Korea (the Republic of)

5 Department of Radiology, Ajou University Hospital, Suwon, Korea (the Republic of)

6 Department of Radiology, University Hospitals Leuven, Belgium

7 Clinic for Diagnostic and Interventional Radiology, Klinikum Stuttgart, Germany

Key words lymphangiography, conventional, postoperative lymphatic leakage, lymph fistula, Lipiodol

received 02.01 .2020

accepted 13.02.2020

Bibliography

Fortschr Röntgenstr 2020; 192: 1025-1035

Published online: 26.3 .2020

DOI 10.1055/a-1131-7889

ISSN 1438-9029

(c) 2020. Thieme. All rights reserved.

Georg Thieme Verlag KG, Rüdigerstraße 14,

70469 Stuttgart, Germany

Correspondence

Dr. Christof M Sommer

Clinic for Diagnostic and Interventional Radiology, University Hospital Heidelberg, INF 110, 69120 Heidelberg, Germany

Tel.: ++49/62 21/5638534

Fax: $++49 / 6221 / 5730$

cmsommer@gmx.com

\section{ZUSAMENFASSUNG}

Hintergrund Die postoperative Lymphleckage (PLL) wird meist konservativ und/oder chirurgisch behandelt, jedoch können diese Behandlungen anspruchsvoll und potenziell klinisch ineffektiv sein. Die konventionelle Lymphangiografie (KL) entwickelte sich zur wichtigen Alternative. Ziel der vorliegenden Übersicht ist es, die verfügbaren Outcome-Daten zur KL beim Management der PLL darzustellen.

Methode Eine systematische Literaturrecherche (PubMed) unter Verwendung des MeSH-Begriffs "lymphangiography” wurde durchgeführt, wobei ausschließlich Artikel berücksichtigt wurden, die zwischen Januar 2007 und August 2019 publiziert wurden. Identifikation, Screening sowie Beurteilung auf Eignung und Einschluss erfolgten in Übereinstimmung mit PRISMA.

Ergebnisse Von den ursprünglich erhaltenen 1006 Artikeln (Identifikation) wurden letztendlich 28 Artikel mit insgesamt 201 Patienten eingeschlossen (Einschluss). Die methodische Qualität aller eingeschlossenen Artikel entspricht Level 4 (Oxford Centre for Evidence-based Medicine - Levels of Evidence, March 2009). Die PLL tritt nach onkologischen und nichtonkologischen Operationen in Form von Chylothorax, chylösem Aszites sowie zervikalen, thorakalen, abdominellen, pelvinen und peripheren Lymphfisteln und/oder Lymphozelen auf. Die technische Erfolgsrate der CL liegt bei 75-100\%. Der Zugang für die CL ist transpedal (176 Patienten) oder intranodal (25 Patienten). Lipiodol wird in allen Artikeln als Kontrastmittel verwendet, mit einer Maximaldosis von $20 \mathrm{ml}$ für die transpedale $\mathrm{CL}$ und 30 ml für die intranodale CL. Röntgen-Bildgebungsmodalitäten beinhalten Fluoroskopie, Radiografie und/oder CT. 2 Artikel berichten über CL-assoziierte Major-Komplikationen sowie CL-assoziierte Morbidität und Mortalität. Die PLL-Abheilungsrate beträgt 51-70\% für die transpedale CL (Abheilungszeit: 2-29 Tage) bzw. 33-100\% für die intranodale CL (Abheilungszeit: $2-<30$ Tage). Rettungsprozeduren im Fall der klinisch ineffektiven $\mathrm{CL}$ beinhalten unterschiedliche Behandlungen.

Schlussfolgerung Die KL ist technisch machbar und sicher und effektiv beim Management der PLL. Lipiodol als Kontrastmittel spielt für die KL eine essenzielle Rolle, da das hochvisköse jodierte Mohnöl nicht nur diagnostische, sondern auch therapeutische Effekte aufweist. Leitlinien und randomisierte kontrollierte Studien sind weitere Schritte, um den tatsächlichen Nutzen der KL zu definieren. 


\section{Kernaussagen:}

- Die PLL ist eine schwer behandelbare und potenziell lebensbedrohliche chirurgische Komplikation.

- Die KL entwickelte sich als Alterative zur konservativen/ operativen Behandlung der PLL.

- Die KL ist technisch machbar und sicher und effektiv beim Management der PLL.

- Die Lipiodol-basierte KL kann als therapeutische Prozedur angesehen werden.

- Leitlinien und randomisierte kontrollierte Studien sind weitere wichtige Schritte.

\section{ABSTRACT}

Background Postoperative lymphatic leakage (PLL) is usually managed by conservative and/or surgical treatments but these procedures can be challenging to perform and potentially clinically ineffective. Therefore, conventional lymphangiography $(\mathrm{CL})$ has emerged as an important alternative. The aim of this review is to present the available outcome data on $\mathrm{CL}$ in the management of PLL.

Method A systematic literature search (PubMed) using the MeSH term "lymphangiography" was performed and the search was restricted to literature published between January 2007 and August 2019. Identification, screening, and assessment for eligibility and inclusion were conducted in accordance with PRISMA.

Results From the initially obtained 1006 articles (identification), 28 articles with a total of 201 patients were finally included (inclusion). The methodological quality of all included articles corresponds to level 4 (Oxford Centre for Evidencebased Medicine - Levels of Evidence, March 2009). PLL occurs after oncological and non-oncological surgery in the form of chylothorax, chylous ascites, and cervical, thoracic, abdominal and peripheral lymph fistula and/or lymphocele. The technical success rate of $\mathrm{CL}$ is $75-100 \%$. Access for $\mathrm{CL}$ is transpedal (176 patients) or intranodal (25 patients). Lipiodol is used as the contrast material in all articles, with a maximum amount of $20 \mathrm{ml}$ for transpedal $\mathrm{CL}$ and $30 \mathrm{ml}$ for intranodal CL. The $\mathrm{X}$-ray imaging modalities used for $\mathrm{CL}$ are fluoroscopy, radiography and/or CT. Two articles report CL-associated major complications and $\mathrm{CL}$-associated morbidity and mortality. The PLL cure rate is $51-70$ \% for transpedal CL (time to PLL cure: 2 29 days) and $33-100 \%$ for intranodal CL (time to PLL cure: $2-$ $<30$ days). Bailout procedures in the case of clinically ineffective $\mathrm{CL}$ include a range of treatments.

Conclusion $\mathrm{CL}$ is feasible, safe, and effective in the management of PLL. Lipiodol as the contrast material is essential in CL because the highly viscous iodinated poppy-seed oil has not only diagnostic but therapeutic effects. Guidelines and randomized controlled trials are further steps towards defining the ultimate value of $\mathrm{CL}$.

\section{Key Points:}

- PLL is a difficult-to-treat and potentially life-threatening surgical complication.

- CL has emerged as an alternative to conservative/surgical treatment of PLL.

- $\mathrm{CL}$ is feasible, safe, and effective in the management of PLL

- Lipiodol-based CL can be regarded as a therapeutic procedure.

- Guidelines and randomized controlled trials are further important steps.

\section{Citation Format}

- Sommer CM, Pieper CC, Itkin M et al. Conventional Lymphangiography $(\mathrm{CL})$ in the Management of Postoperative Lymphatic Leakage (PLL): A Systematic Review. Fortschr Röntgenstr 2020; 192: 1025-1035

\section{Introduction}

Different types of surgical procedures may injure lymph ducts and lymph nodes, resulting in postoperative lymphatic leakage (PLL) as a difficult-to-treat and potentially life-threatening complication [1]. PLL can occur anywhere in the body along the lymphatic system, leading to the pathological accumulation of lymph or chyle (e.g. chylothorax and lymphatic ascites or chylous ascites) $[1,2]$. Lymph can also leak through percutaneous tracts in the form of a lymph fistula, which is associated with or without diffuse or localized lymph collections (e.g. lymphocele) [3]. Refractory PLL can significantly affect postoperative recovery time, wound healing, and quality of life. High-output PLL increases morbidity and mortality among patients due to lymphocytopenia, protein loss, fat loss, malnutrition, respiratory distress, and immune suppression [1, 3-5]. For the past three decades, conservative and surgical treatments have defined the standard for managing PLL. Conservative management includes parenteral nutrition, medium-chain triglycerides diet, administration of somatostatin analo- gues (e.g. octreotide), repeated paracentesis, and percutaneous drainage procedures. Surgical management comprises different and at least in parts non-standardized approaches such as lymph duct ligation, shunt implantation, sclerotherapy with doxycycline or thrombin, plastic surgery, and wound vacuum therapy $[6,7]$. Depending on the type, degree and location of PLL, both conservative and surgical management can be challenging to perform, time-consuming and expensive as well as clinically ineffective, whereby surgery-related complication and mortality rates of up to $38 \%$ and $25 \%$, respectively, have been described [1, 3, 4, 6, $8-13]$. Conventional lymphangiography $(\mathrm{CL})$, a radiological examination performed under $\mathrm{X}$-ray imaging after contrast material injection, has emerged as an alternative to the aforementioned treatments. In different articles, $\mathrm{CL}$ was described as a minimally invasive diagnostic tool for determining the precise location of the PLL but more importantly there are multiple articles outlining the therapeutic effects of $C L[3,4,10,14-17]$. Although $C L$ is increasingly applied in clinical practice, the technique, safety, and efficacy have not been analyzed in a systematic review. In this article, 
the available outcome data on CL in the management of PLL as published between January 2007 and August 2019 are presented and catalogued with comments.

\section{Materials and Methods}

Our systematic review is conducted according to the Preferred Reporting Items for Systematic Reviews and Meta-Analyses (PRISMA) statement for systematic reviews [18]. A literature search was performed up to September 2019 in the PubMed database, using the Medical Subject Heading (MeSH) term "lymphangiography”. The search was restricted to literature published between January 2007 and August 2019. Titles and abstracts of retrieved articles were screened for data on $\mathrm{CL}$, and defined as lymphangiography performed under X-ray imaging after contrast material injection. Full-length articles including reference lists of potentially relevant articles were evaluated for eligibility based on the following inclusion criteria: Only publications with original data on $\mathrm{CL}$ performed in the management of PLL were included. The following exclusion criteria were defined: (I) Alternative lymphangiography techniques (e. g. MR lymphangiography and indocyanine green lymphangiography), (II) CL performed in combination with second-line lymphatic interventions (e. g. thoracic duct embolization or interstitial embolization), (III) lack of adequate reporting of methodological details, and (IV) publication language other than English or German. Primary data extraction was performed by two experienced interventional radiologists, each with $>10$ years of experience in $\mathrm{CL}$. Data were then reviewed and evaluated by all authors, and discrepancies were resolved by consensus. For better clarity and to increase the scientific informative value of the systematic review, the articles that were finally included were organized according to the number of patients that were included in the different articles: Category I data - large original case series (>10 patients); Category II data -small original case series (3-9 patients); Category III data - case reports and other short reports such as letters to the editor and technical notes ( $<3$ patients). Category I data were first analyzed, and then the analysis was extended to Category II data. Outcome data with a special focus on clinical background and indications, technical aspects, complications, morbidity and mortality, PLL cure rate after $\mathrm{CL}$, and bailout procedures in case of clinically ineffective $\mathrm{CL}$ were presented under results in the main body as well as in the form of tables. Category III data were summarized in the main body, whereby new or relevant additional information (e. g. new clinical indications, innovative technical aspects, or complications, morbidity or mortality) was emphasized.

\section{Definition of Technical Success}

Technical success of $\mathrm{CL}$ was defined as successful injection of the contrast material with the intention to selectively visualize the lymphatic system and the lymphatic pathology under X-ray imaging.

\section{Definition of PLL Cure}

As written in the different articles, PLL cure was defined as clinical disappearance of the PLL after CL without the need for further intervention.

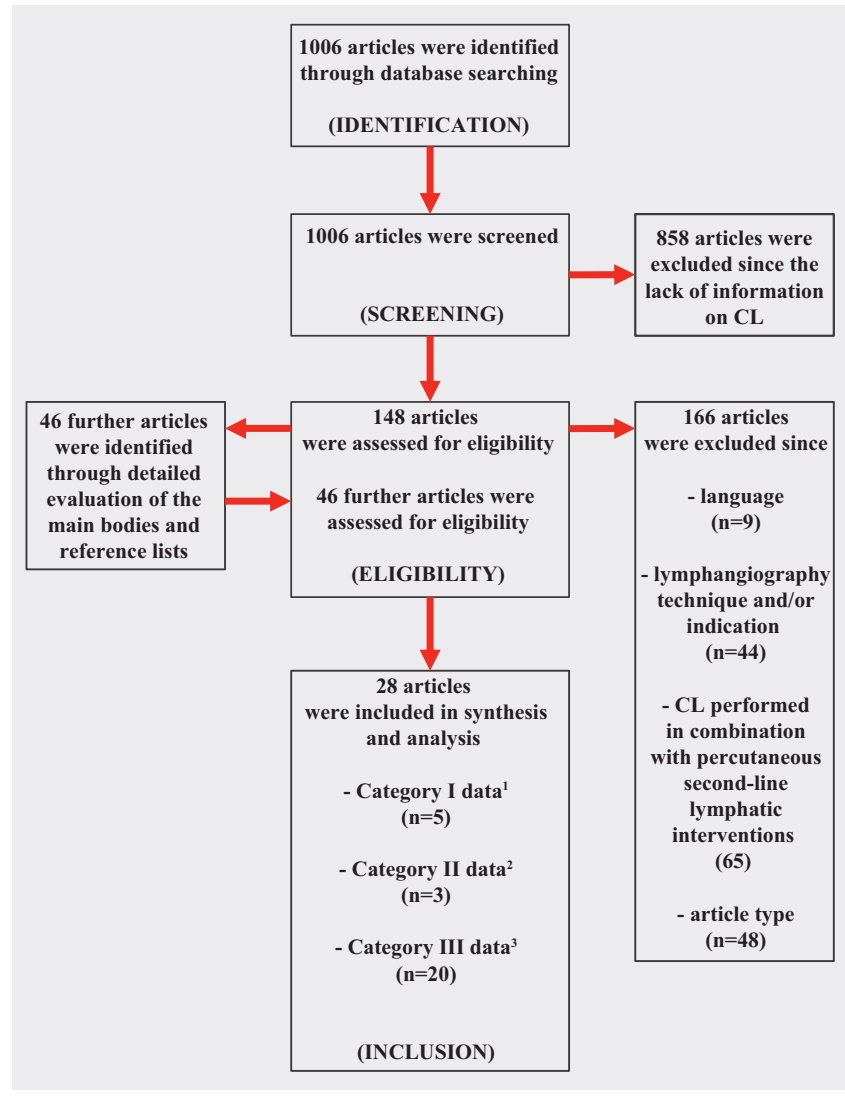

- Fig. 1 Flow Chart on the Selection of Articles. Note: ${ }^{1}$ Category I data - large original case series ( $>10$ patients); ${ }^{2}$ Category II data small original case series (3-9 patients); ${ }^{3}$ Category III data - case reports and other short reports such as letters to the editor and technical notes ( $<3$ patients).

- Abb. 1 Flussdiagramm mit Selektion der Artikel.

\section{Results}

\section{Literature Search and Selection}

From the initially obtained 1006 articles, 858 were excluded due to the lack of information on CL. The remaining 148 articles as well as 46 further articles identified through detailed evaluation of the main bodies and reference lists were assessed for eligibility. Of these 194 articles, 166 articles not fulfilling the inclusion criteria or fulfilling the exclusion criteria were excluded. Finally, 28 articles with a total of 201 patients were included for detailed analyses ( $\triangleright$ Fig. $\mathbf{1}$ ). These 28 articles included 5 large original case series with > 10 patients (Category I data) and 3 small original case series with 3-9 patients (Category II data) [15, 19-25]. The other 20 articles included were case reports and other short reports such as letters to the editor and technical notes with $<3$ patients (Category III data) [14, 17, 26-43]. None of these articles included a prospective study or a randomized controlled trial. The methodological quality of all included articles corresponds to level 4 of the Oxford Centre for Evidence-based Medicine - Levels of Evidence, March 2009. 


\section{Outcome Data}

Clinical Background and Indications of CL

Under consideration of Category I data and Category II data, PLL occurs after oncological (e. g. esophagectomy and radical prostatectomy) and non-oncological (e.g. thoraco-abdominal aortic repair and kidney transplantation) surgery of the thorax, abdomen, pelvis and spine. The clinical presentation of PLL is chylothorax and chylous ascites as well as cervical, thoracic, abdominal and peripheral lymph fistula and/or lymphocele. The PLL volume is $10-3000 \mathrm{ml} /$ day. Failed pretreatments to cure PLL include a range of procedures such as conservative management (e.g. compression bandage and total parenteral nutrition), conservative treatments (e.g. somatostatin analogues and sympathomimetic drugs), minimally invasive procedures (e. g. drainage/paracentesis and percutaneous thoracic duct embolization), and surgical management (e. g. surgical exploration). The interval "causal surgery - CL" is 1-183 days. Data are catalogued in > Table 1.

Under consideration of Category III data, further types of causal surgery include different conventional (e. g. hemihepatectomy) and minimally invasive (e. g. exploratory laparoscopy including peritoneal washing and omental and peritoneal biopsies) procedures [31, 41]. Compared with Category I data and Category II data, the clinical presentation of PLL is extended, and includes also chyluria and a PLL volume of up to $6000 \mathrm{ml} /$ day [26, 32]. As for Category I data and Category II data, failed pretreatments to cure PLL include a range of procedures such as conservative management (e.g. low fat/high protein enteral nutrition and factor XIII products [ $20 \mathrm{ml} /$ day for 5 days]), percutaneous radiation therapy (midabdominal area [20 Gy for 2 weeks]), minimally invasive procedures (e.g. interstitial embolization by applying glue after intranodal $\mathrm{CL}$ ), and surgical management (e. g. peritoneal-venous shunt implantation) [26, 33, 36, 38].

\section{Technical Aspects of CL}

Under consideration of Category I data and Category II data, the technical success rate of $\mathrm{CL}$ is $75-100 \%$, whereby reasons for technical failure include the inability to inject the contrast material selectively into the lymphatic system. Access for $C L$ is transpedal for Category I data as well as intranodal (groin, neck and axilla) for Category II data. Lipiodol, injected selectively with a maximum injection speed of $0.13 \mathrm{ml} / \mathrm{min}$ for transpedal $\mathrm{CL}$ and $0.33 \mathrm{ml} / \mathrm{min}$ for intranodal $\mathrm{CL}$, is used as the contrast material in all articles. The maximum amount of Lipiodol is $20 \mathrm{ml}$ for transpedal $\mathrm{CL}$ and $15 \mathrm{ml}$ for intranodal $\mathrm{CL}$, irrespective of whether unilateral or bilateral $\mathrm{CL}$ was performed. The $\mathrm{X}$-ray imaging modalities used for $\mathrm{CL}$ are fluoroscopy and radiography in $8 / 8$ articles, and additionally $\mathrm{CT}$ in 5/8 articles. The time point of X-ray imaging to visualize the PLL is the filling phase in $8 / 8$ articles, and additionally the nodal phase in 6/8 articles. X-ray imaging signs of PLL include direct signs (pathological contrast material extravasation) and/or indirect signs (e. g. pathological contrast material pooling and atypical opacification of the lymph ducts as a sign of lymphatic collateralization). Data are catalogued in $\mathbf{~ T a b l e ~} 2$.

Under consideration of Category III data, the technical success rate of $\mathrm{CL}$ is $100 \%$ in 20/20 articles, whereby in 1 article groin intranodal CL was performed under CT guidance and with a $1 \mathrm{ml}$ test injection of water-soluble iodinated contrast material because ultrasound-guided puncture of the inguinal lymph nodes was not feasible (due to the patient's thick edematous skin preventing precise detection and tapering of the inguinal lymph nodes). Access for $\mathrm{CL}$ is transpedal in 5/20 articles and intranodal (groin) in 14/20 articles. In 1/20 articles, intranodal (mesentery) was the access for $\mathrm{CL}$ [38]. Lipiodol is used as the contrast material in all articles, being injected selectively with a maximum injection speed of $0.14 \mathrm{ml} / \mathrm{min}$ for transpedal $\mathrm{CL}$ and $0.5 \mathrm{ml} / \mathrm{min}$ for intranodal CL $[41,43]$. The maximum amount of Lipiodol is $12 \mathrm{ml}$ for transpedal $\mathrm{CL}$ and $30 \mathrm{ml}$ for intranodal $\mathrm{CL}$, irrespective of whether unilateral or bilateral $\mathrm{CL}$ was performed [30, 36]. X-ray imaging modalities used for $\mathrm{CL}$, time point of $\mathrm{X}$-ray imaging to visualize the PLL and X-ray imaging signs of PLL are comparable with Category I data and Category II data.

\section{Complications, Morbidity, and Mortality during/after CL}

Under consideration of Category I data and Category II data, 5 articles specify complications, morbidity and mortality during/after CL. CL-related minor and major complication rates are $0-3 \%$ and $0 \%$ for transpedal $C L$ as well as $0 \%$ and $0 \%$ for intranodal $C L$, respectively. One article described $\mathrm{CL}$-associated minor complications (contrast material emboli in the pulmonary artery in 2 patients) after transpedal CL [20]. 30-day CL-related morbidity and mortality rates are $0 \%$ and $0 \%$ for transpedal $C L$ as well as $0 \%$ and $0 \%$ for intranodal $\mathrm{CL}$, respectively. Data are catalogued in

\section{Table 3.}

Under consideration of Category III data, the complication, morbidity and mortality rates during/after CL can be regarded as low, as is the case for Category I data and Category II data. CLrelated minor and major complication rates are $0 \%$ and $0 \%$ in $13 / 20$ articles (and n.s. in 5/20 articles). The 30-day CL-related morbidity rate is $0 \%$ in $9 / 20$ articles (and n.s. for $10 / 20$ articles) $[28,36-40,42,43]$. The 30 -day CL-related mortality rate is $0 \%$ in 10/20 articles (and n.s. for 8/20 articles) [28, 32, 33, 36-40, 42, 43]. In 2 articles, however, significant complications, morbidity and/or mortality are described $[29,41]$. In the article of Taki et al., acute respiratory distress syndrome was reported as a $\mathrm{CL}$-related major complication after transpedal $\mathrm{CL}$, and the patient developed pulmonary fibrosis necessitating domiciliary oxygen therapy due to permanent hypoxemia [41]. In the article of Sheybani et al., Lipiodol embolization to the brain and to the lung was reported as a CL-related major complication after intranodal $\mathrm{CL}$, and the patient died 69 days after $\mathrm{CL}$ (because all supportive care was withdrawn due to a very low probability of meaningful recovery after a complicated clinical course including deteriorating mental status and pneumonia) [29].

\section{PLL Cure Rate after CL and Bailout Procedures}

Under consideration of Category I data and Category II data, the PLL cure rate is $51-70 \%$ for transpedal CL and $33-100 \%$ for intranodal CL. Subgroup analyses as performed in the original articles present a deeper insight into the PLL cure rates. For the patients without surgical revision $<4$ weeks after transpedal CL, Kos et al. described a PLL cure rate of $75 \%$ for chylothorax, $86 \%$ for lymph 


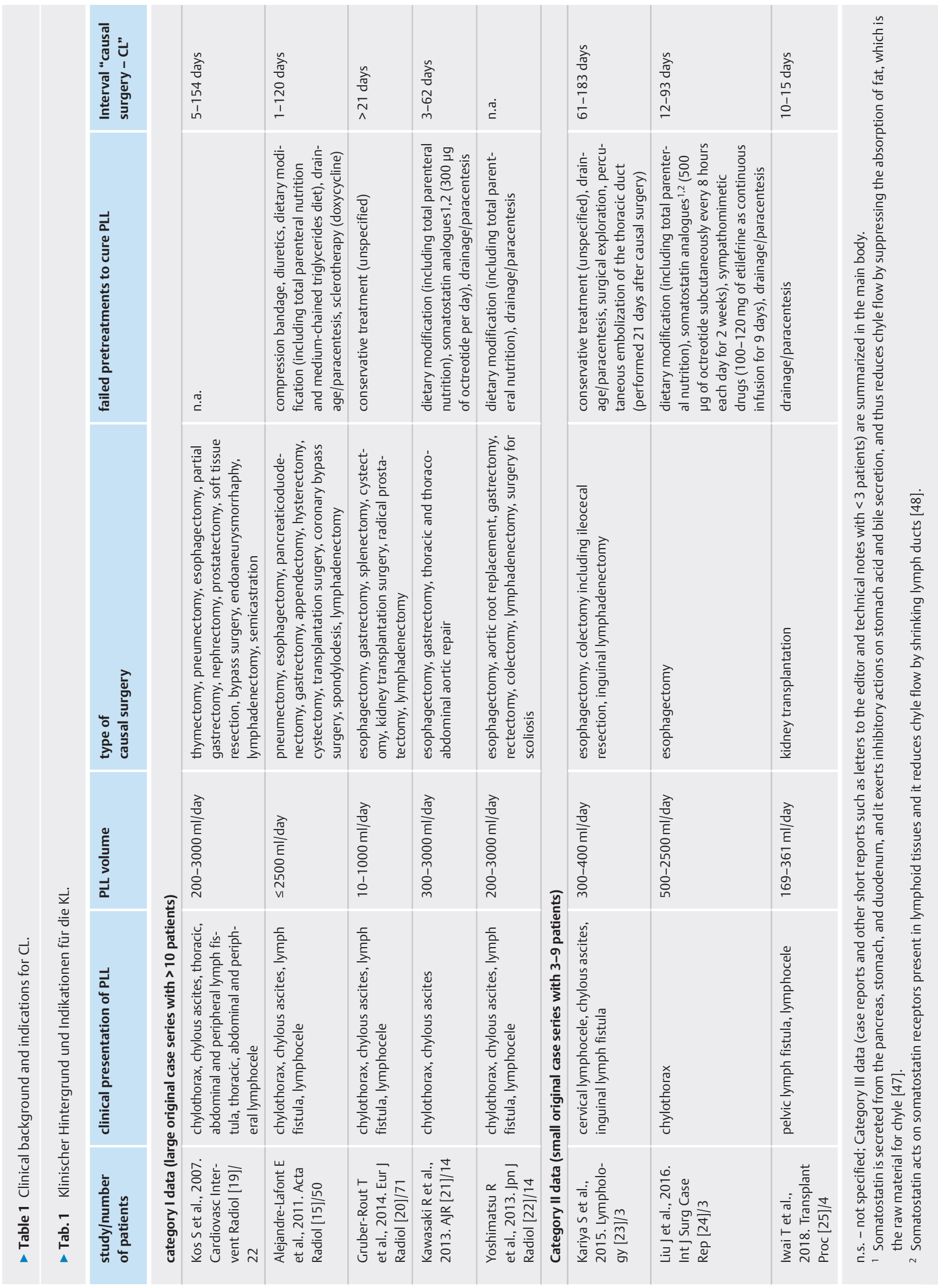




\begin{tabular}{|c|c|c|c|c|c|c|c|c|c|}
\hline & 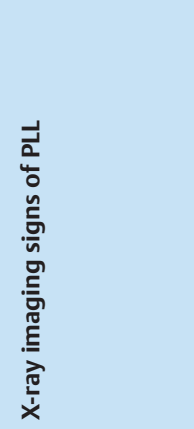 & & 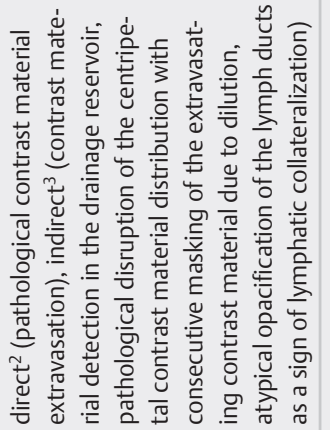 & $\begin{array}{l}0 \\
\vdots \\
\dot{0} \\
\dot{c}\end{array}$ & $\stackrel{\dot{\varphi}}{\check{C}}$ & 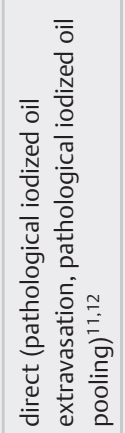 & 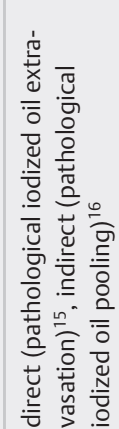 & & 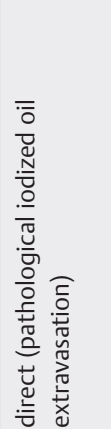 \\
\hline & 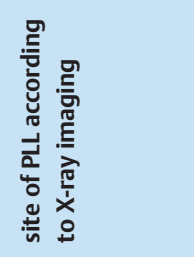 & & 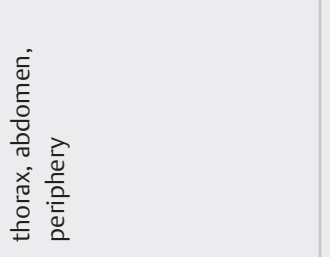 & 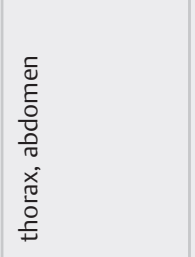 & $\dot{\stackrel{⿹}{\check{c}}}$ & $\stackrel{\dot{g}}{\check{c}}$ & $\stackrel{\dot{\varphi}}{\check{c}}$ & & 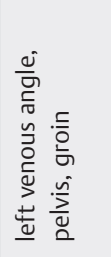 \\
\hline & 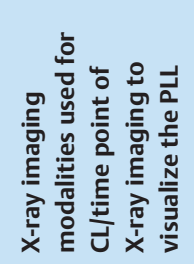 & & 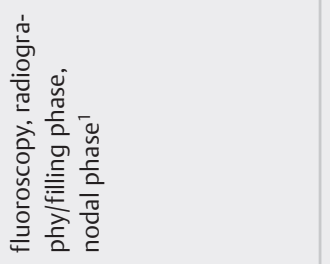 & 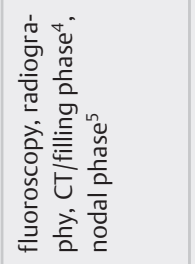 & 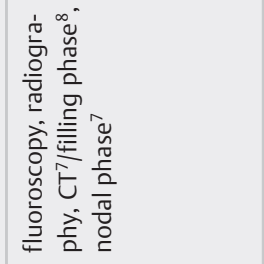 & 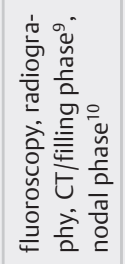 & 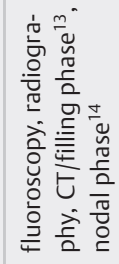 & & 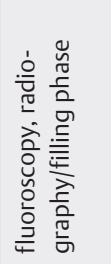 \\
\hline & 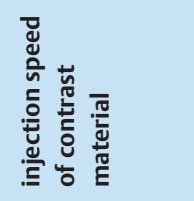 & & 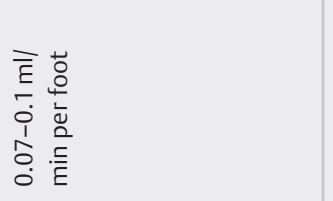 & 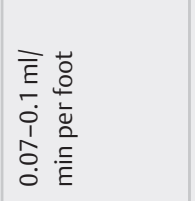 & $\begin{array}{l}\overline{\bar{\varepsilon}} \\
m \\
\frac{0}{0} \\
\frac{1}{o} \cdot \frac{\bar{E}}{\bar{b}}\end{array}$ & $\stackrel{ர ்}{\check{\check{C}}}$ & $\frac{\frac{c}{\bar{E}}}{\frac{\bar{E}}{\bar{E}}}$ & & 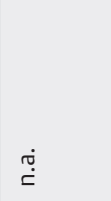 \\
\hline & 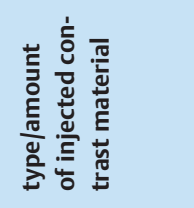 & & 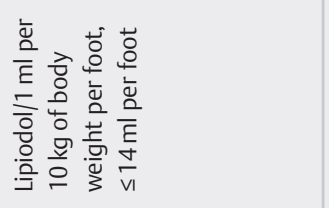 & 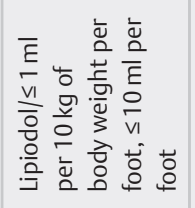 & 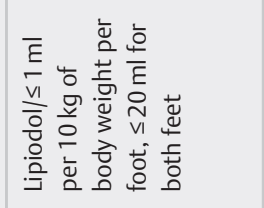 & 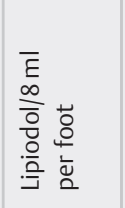 & 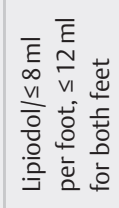 & & $\begin{array}{l}\bar{E} \\
\underline{1} \\
\frac{1}{\overline{0}} \\
\overline{\overline{0}} \\
. \frac{0}{\Xi}\end{array}$ \\
\hline & 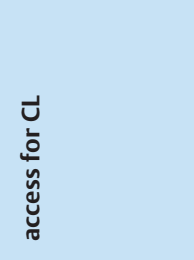 & 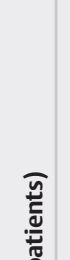 & 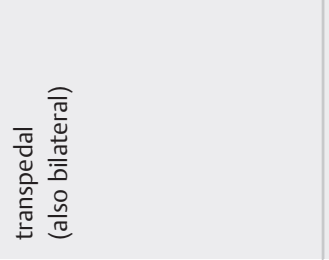 & 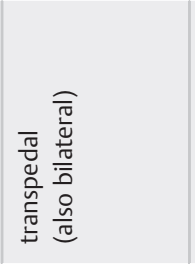 & 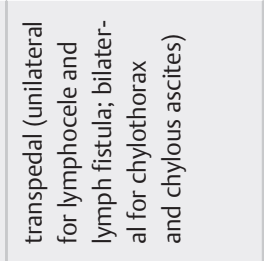 & 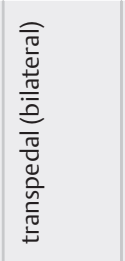 & 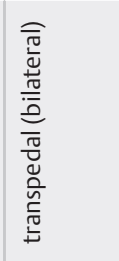 & 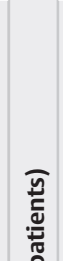 & 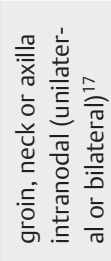 \\
\hline $\begin{array}{l}\frac{\vec{v}}{\bar{v}} \\
\frac{\bar{v}}{y} \\
\frac{\vec{v}}{q}\end{array}$ & 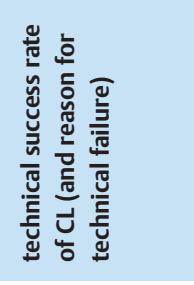 & 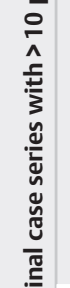 & 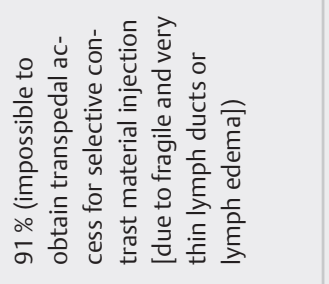 & 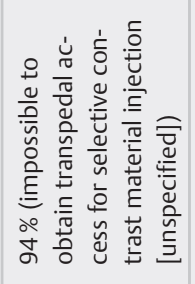 & 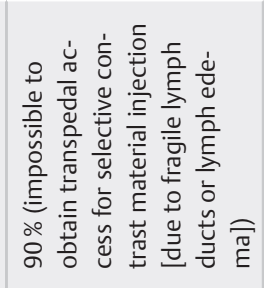 & $\frac{1}{\stackrel{1}{\circ}}$ & $\begin{array}{l}I \\
\stackrel{I}{\circ} \\
\stackrel{\circ}{\circ}\end{array}$ & 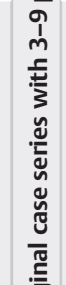 & $\stackrel{\circ}{\circ}$ \\
\hline 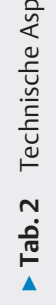 & 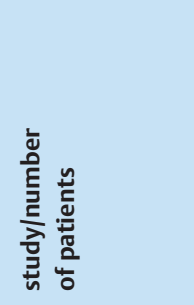 & 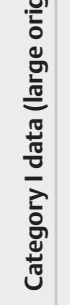 & 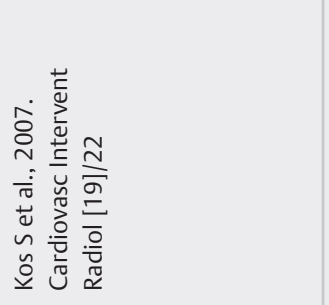 & 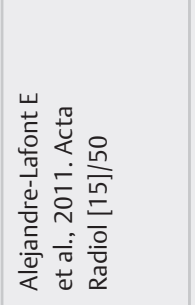 & 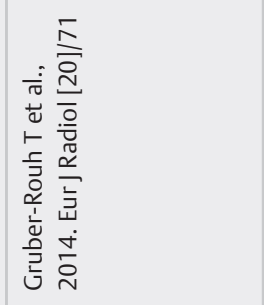 & 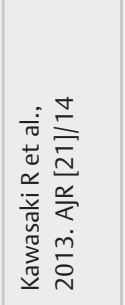 & 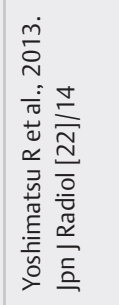 & 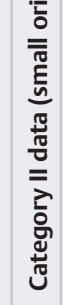 & 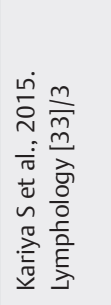 \\
\hline
\end{tabular}




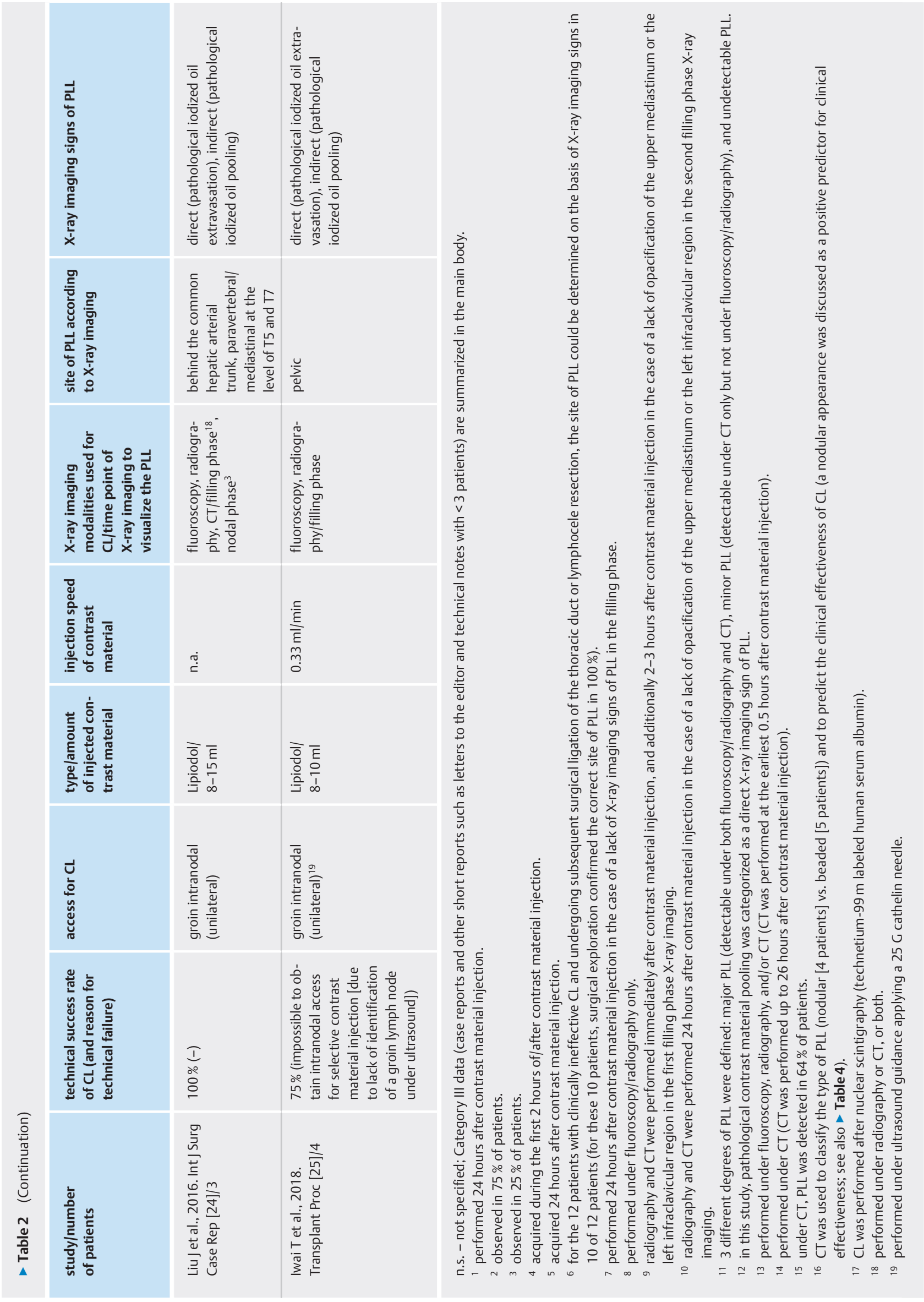


- Table 3 Complications, morbidity, and mortality during/after CL.

- Tab.3 Komplikationen, Morbidität und Mortalität während/nach KL.

\begin{tabular}{|c|c|c|c|c|c|c|}
\hline $\begin{array}{l}\text { study/number } \\
\text { of patients }\end{array}$ & $\begin{array}{l}\text { CL-related minor } \\
\text { complications }\end{array}$ & $\begin{array}{l}\text { CL-related major } \\
\text { complications }\end{array}$ & $\begin{array}{l}\text { 30-day CL-related } \\
\text { morbidity }\end{array}$ & $\begin{array}{l}\text { 30-day } \\
\text { CL-related } \\
\text { mortality }\end{array}$ & $\begin{array}{l}\text { overall } \\
\text { morbidity }\end{array}$ & $\begin{array}{l}\text { overall } \\
\text { mortality }\end{array}$ \\
\hline \multicolumn{7}{|c|}{ category I data (large original case series with $>10$ patients) } \\
\hline $\begin{array}{l}\text { Kos S et al., 2007. Cardiovasc } \\
\text { Intervent Radiol [19]/22 }\end{array}$ & n.s. & n.s. & n.s. & n.s. & n.s. & n.s. \\
\hline $\begin{array}{l}\text { Alejandre-Lafont E et al., } 2011 . \\
\text { Acta Radiol [15]/50 }\end{array}$ & n.s. & n.s. & n.s. & n.s. & n.s. & n.s. \\
\hline $\begin{array}{l}\text { Gruber-Rouh T et al., 2014. Eur } \\
\text { J Radiol [20]/71 }\end{array}$ & $3 \%^{1}$ & $0 \%$ & n.s. & $0 \%$ & n.s. & n.s. \\
\hline $\begin{array}{l}\text { Kawasaki R et al., 2013. AJR } \\
{[21] / 14}\end{array}$ & $0 \%$ & $0 \%$ & $0 \%$ & $0 \%$ & n.s. & n.s. \\
\hline $\begin{array}{l}\text { Yoshimatsu R et al., 2013. Jpn J } \\
\text { Radiol [22]/14 }\end{array}$ & $0 \%$ & $0 \%$ & n.s. & n.s. & n.s. & n.s. \\
\hline \multicolumn{7}{|c|}{ category II data (small original case series with 3-9 patients) } \\
\hline $\begin{array}{l}\text { Kariya S et al., } 2015 . \\
\text { Lymphology [44]/3 }\end{array}$ & n.s. & n.s. & n.s. & n.s. & n.s. & n.s. \\
\hline $\begin{array}{l}\text { Liu J et al., 2016. Int J Surg Case } \\
\text { Rep [24]/3 }\end{array}$ & $0 \%$ & $0 \%$ & n.s. & n.s. & n.s. & n.s. \\
\hline $\begin{array}{l}\text { Iwai T et al., 2018, Transplant } \\
\text { Proc [25]/4 }\end{array}$ & $0 \%$ & $0 \%$ & $0 \%$ & $0 \%$ & n.s. & n.s. \\
\hline
\end{tabular}

fistula, and $0 \%$ for lymphocele [19]. After transpedal CL, Alejandre-Lafont et al. observed a PLL cure rate of $70 \%$ for the patients with a PLL volume of $<500 \mathrm{ml} /$ day compared with $35 \%$ for the patients with a PLL volume of $>500 \mathrm{ml} /$ day [15]. GruberRouh et al. presented a PLL cure rate of $96.8 \%$ for the patients with a PLL volume of $<200 \mathrm{ml} /$ day compared with $58.1 \%$ for the patients with a PLL volume of $>200 \mathrm{ml} /$ day after transpedal $\mathrm{CL}$ [20]. Kawasaki et al. could achieve a PLL cure in 2 of 7 major PLLs (annotation: major PLLs were defined as detectable under both fluoroscopy/radiography and (T) as well as in all minor PLLs (annotation: minor PLLs were defined as detectable under CT only but not under fluoroscopy/radiography) and undetectable PLLs after transpedal CL [21]. Kariya et al. repeated intranodal $\mathrm{CL}$ once in a patient with cervical lymphocele (22 days after the first intranodal $\mathrm{CL}$ ), once in a patient with chylous ascites (4 days after the first intranodal $\mathrm{CL}$ ), and 3 times in a patient with a lymph fistula in the groin $(4,10$, and 17 days after the first intranodal $C L)$ which resulted in a PLL cure rate of $100 \%$ [44]. Time to PLL cure is 3-29 days for transpedal CL and 2-20 days for intranodal CL. Bailout procedures in the case of clinically ineffective $\mathrm{CL}$ include a range of treatments such as conservative management and surgical revision (e. g. lymph duct ligation and lymphocele fenestration). Data are catalogued in $>$ Table 4.
Under consideration of Category III data, the PLL cure rate is $100 \%$ in 4 articles with transpedal CL and 14 articles with intranodal CL (and n.s. in 2/20 articles [1 article with transpedal CL and 1 article with intranodal CL]) [17, 26-28, 30-43]. In the article of Hara et al. with 1 patient with chylothorax (PLL volume of $1000 \mathrm{ml} /$ day), intranodal CL was performed twice at an interval of 1 month (bilateral groin access for the first $C L$ and bilateral groin and bilateral axilla access for the second $\mathrm{CL}$ ) until PLL cure was observed [37]. The time to PLL cure is 2-5 days for transpedal $\mathrm{CL}$ and $3-<30$ days for intranodal $\mathrm{CL}$.

\section{Comment}

In this systematic review, the outcome data regarding $\mathrm{CL}$ in the management of PLL have been presented and catalogued with comments. On the basis of Category III data, no firm conclusions can be drawn, but Category I data and Category II data suggest that $C L$ is feasible, safe, and effective. $C L$ is performed in the management of PLL occurring in multiple different locations. Accordingly, clinical background and indications are inconsistent: Type of PLL (e. g. peripheral percutaneous lymph fistula, pelvic lymphocele, or chylothorax), PLL volume (ranging from $10 \mathrm{ml} /$ day to $6000 \mathrm{ml} /$ day), type of causal surgery (e. g. exploratory laparoscopy including biopsy, hemihepatectomy, kidney transplantation, 
- Table 4 PLL cure rate after CL and bailout procedures.

- Tab.4 PLL-Abheilungsrate nach KL und Rettungsprozeduren.

\begin{tabular}{|c|c|c|c|c|}
\hline study/number of patients & PLL cure rate after CL & $\begin{array}{l}\text { time to PLL } \\
\text { cure }\end{array}$ & $\begin{array}{l}\text { follow-up in- } \\
\text { terval after CL }\end{array}$ & $\begin{array}{l}\text { bailout procedures in case of } \\
\text { clinically ineffective } \mathrm{CL}\end{array}$ \\
\hline \multicolumn{5}{|c|}{ category I data (large original case series with $>10$ patients) } \\
\hline $\begin{array}{l}\text { Kos S et al., 2007. Cardiovasc } \\
\text { Intervent Radiol [19]/22 }\end{array}$ & $55 \%{ }^{1}$ & 21-28 days & n.s. ${ }^{2}$ & $\begin{array}{l}\text { surgical occlusion of the thoracic duct, lymphocele } \\
\text { fenestration (inclusive of insertion of a Salem } \\
\text { drain), wound debridement }\end{array}$ \\
\hline $\begin{array}{l}\text { Alejandre-Lafont E et al., } 2011 . \\
\text { Acta Radiol [15]/50 }\end{array}$ & $51 \%^{3}$ & $\leq 14$ days & n.s. & $\begin{array}{l}\text { surgical ligation of the thoracic duct, lymphocele } \\
\text { resection }\end{array}$ \\
\hline $\begin{array}{l}\text { Gruber-Rouh T et al., 2014. Eur } \\
\text { J Radiol [20]/71 }\end{array}$ & $70 \% 4$ & $10-28$ days & $1-24$ months & surgical occlusion of the $\mathrm{PLL}^{5}$ \\
\hline $\begin{array}{l}\text { Kawasaki R et al., 2013. AJR } \\
\text { [21]/14 }\end{array}$ & $64 \%{ }^{6}$ & 3-29 days & 12-104 days & surgical pleurodesis, surgical thoracic duct ligation \\
\hline $\begin{array}{l}\text { Yoshimatsu R et al., 2013. Jpn J } \\
\text { Radiol [22]/14 }\end{array}$ & $57 \%$ & n.s. & n.s. & surgical pleuro-sclerosis, conservative treatment \\
\hline \multicolumn{5}{|c|}{ Category II data (small original case series with 3-9 patients) } \\
\hline $\begin{array}{l}\text { Kariya S et al., } 2015 . \\
\text { Lymphology [44]/3 }\end{array}$ & $100 \% 7,8$ & $2-14$ days & n.s. & - \\
\hline $\begin{array}{l}\text { Liu J et al., 2016. Int J Surg Case } \\
\text { Rep [24]/3 }\end{array}$ & $33 \%$ & 20 days & n.s. & surgical lymph duct ligation 9,10 \\
\hline $\begin{array}{l}\text { Iwai T et al., 2018. Transplant } \\
\text { Proc [25]/4 }\end{array}$ & $100 \%$ & $8-13$ days & 8-16 months & n.s. \\
\hline \multicolumn{4}{|c|}{$\begin{array}{l}\text { n.s. - not specified; Category III data (case reports and other short reports such as letters to the editor and technical notes with }<3 \text { patients) are } \\
\text { summarized in the main body. } \\
1 \text { for the patients without surgical revision }<4 \text { weeks after CL, the PLL cure rate after CLL was } 69.2 \% \text { ( } 75 \% \text { for chylothorax, } 86 \% \text { for lymph fistula and } 0 \% \text { for } \\
\text { lymphocele). } \\
2 \text { PLL recurrence after } 8 \text { wks in } 1 \text { patient with combined chylothorax/chylous ascites initially treated effectively with CL. } \\
{ }^{3} \mathrm{PLL} \text { cure rate of } 70 \% \text { for the patients with a PLL volume of }<500 \mathrm{ml} / \text { day compared with } 35 \% \text { for the patients with a PLL volume of }>500 \mathrm{ml} / \mathrm{day} \text {. } \\
{ }^{4} \mathrm{PLL} \text { cure rate of } 96.8 \% \text { for the patients with a PLL volume of }<200 \mathrm{ml} / \text { day compared with } 58.1 \% \text { for the patients with a PLL volume of }>200 \mathrm{ml} / \mathrm{day} \text {. } \\
5 \text { performed on the basis of X-ray imaging presenting degree and location of PLL. }\end{array}$} & $\begin{array}{l}\text { I and technical notes with }<3 \text { patients) are } \\
5 \% \text { for chylothorax, } 86 \% \text { for lymph fistula and } 0 \% \text { for } \\
\text { ffectively with CL. } \\
\text { patients with a PLL volume of }>500 \mathrm{ml} / \text { day. } \\
\text { the patients with a PLL volume of }>200 \mathrm{ml} / \text { day. } \\
\text { well as cure in all minor (defined as detectable under } \\
\text { the patient with the chylous ascites } 4 \text { days after the } \\
\text { st CL. } \\
\text { ays after CL (showing a time to PLL cure of } 16 \text { and }\end{array}$ \\
\hline
\end{tabular}

or esophagectomy), failed pretreatments to cure PLL (ranging from conservative management [e. g. dietary modification] to surgical revision [e.g. wound vacuum therapy]), and interval "causal surgery - CL" (ranging from 1 day to 4 years). Regarding technical aspects, transpedal $\mathrm{CL}$ and groin intranodal $\mathrm{CL}$ are the most frequently used accesses, both being performed with a high technical success rate and with Lipiodol as the contrast material. Lipiodol is a highly viscous ethyl ester of iodinated poppyseed oil fatty acid with the potential to not only visualize but also to cure the PLL $[45,46]$. There are two potential mechanisms leading to PLL cure: Lipiodol-induced selective blockage of the leaking lymph ducts and/or lymph nodes as well as induction of a sterile inflammation process with subsequent scarring at the site of the pathological Lipiodol extravasation leading to closure of the PLL over time [16, 25]. Alternative access for intranodal $C L$ is the neck, axilla and the mesentery [37, 38, 44]. X-ray imaging modalities that are regularly used for $\mathrm{CL}$ are not only fluoroscopy and radiography but also $C T$, the latter demonstrating also the subtledirect (pathological contrast material extravasation) and indirect (e. g. pathological contrast material pooling) signs of PLL, especially in complex anatomic regions (e.g. thorax or abdomen) [21]. The time point or window of X-ray imaging with which to visualize the PLL is the filling phase (performed during contrast material propagation into the central lymphatic system), and additionally the nodal phase (performed in multiple articles 24 hours after contrast material injection if X-ray imaging in the filling 
phase remains unclear). Transpedal and intranodal $C L$ can be regarded as safe procedures. $\mathrm{CL}$-associated complications are occasional and in the vast majority of cases there are minor complications that are self-limiting or well manageable with standard treatment. Contrast material emboli in the pulmonary artery are a relevant complication. However, this was rated as a minor complication due to the lack of clinical sequelae in 1 article [20]. CL-associated morbidity and mortality are extremely rare, but were described in 1 article with acute respiratory distress syndrome and in 1 article with cerebral contrast material embolism, respectively $[29,41]$. The PLL cure rate after $C L$ - as written in the different articles - should be interpreted with caution. With respect to Category I data and Category II, the PLL cure rate is indicated as $51-70 \%, 57-64 \%$ and $33-100 \%$, respectively $[15,19-22,24,25$, 44]. However, these data do not necessarily consider the rate of technical failure. After recalculation under specific consideration of the rate of technical failure of $C L$, the real PLL cure rate - the PLL cure rate on an intent-to-treat basis - decreases in 3/5 articles for Category I data (from $55 \%$ to $50 \%$, from $51 \%$ to $48 \%$ and from $70 \%$ to $63 \%$, respectively) and in $1 / 3$ articles for Category II data (from $100 \%$ to $75 \%$ ) [15, 19, 20, 25]. The predictors of PLL cure after CL include PLL volume, PLL morphology, and type of PLL. PLL volumes of $>500 \mathrm{ml} /$ day or $>200 \mathrm{ml} /$ day are associated with decreased PLL cure rates [15, 20]. Minor PLLs detectable under CT only (but not under fluoroscopy/radiography) are associated with increased PLL cure rates [21]. CL for the treatment of lymphoceles is associated with decreased PLL cure rates [15, 19]. Practical experience, however, repeatedly shows that the aforementioned positive and negative predictors of clinical success are not necessarily reliable. Notwithstanding, one cannot emphasize enough the fact that one or multiple repetitions of $C L$ can lead to an increased PLL cure rate as was demonstrated by Kariya $\mathrm{S}$ et al. and Hara $\mathrm{H}$ et al. $[37,44]$. Bailout procedures after clinically ineffective $\mathrm{CL}$ include conservative management and different types of surgical treatments (e. g. thoracic duct ligation, wound debridement and lymphocele fenestration). Interestingly, second-line percutaneous lymphatic interventions such as thoracic duct embolization by applying coils or interstitial embolization by applying glue are not mentioned as bailout procedures [3, 45]. A possible explanation is that the different second-line percutaneous lymphatic interventions are performed virtually always in combination with $C L$, whereby $C L$ is then intended exclusively to visualize the lymphatic system (e.g. cisterna chyli) and the lymphatic pathology (e.g. leaking lymph ducts and/or lymph nodes) to guide specifically subsequent second-line percutaneous lymphatic interventions $[3,9,10,13,45]$. Because of the multiple types and high complexity of second-line percutaneous lymphatic interventions, presentation of these outcome data would exceed the scope of this manuscript and therefore they were not considered in this review (according to the exclusion criteria). However, a dedicated systematic review of articles with second-line percutaneous lymphatic interventions is strongly warranted and should be performed and published in the near future.

The primary limitation of this systematic review is the source data itself, which are available on the level of study data but not on the level of patient data. All analyzed articles are retrospective analyses with limited sample size and, therefore, the presented level of evidence is low (level 4 of the Oxford Centre for Evidence-based Medicine - Levels of Evidence, March 2009). The lack of standardization of reporting criteria and terminology impedes the precise communication in the field of $\mathrm{CL}$, which has to be listed as another limitation. These facts made the implementation of a meta-analysis of the presented original data impossible. Nevertheless, detailed analysis of the 28 articles was performed in order to present the status quo of $\mathrm{CL}$ in the management of PLL as accurately as possible.

In conclusion, $\mathrm{CL}$ is feasible, safe, and effective in the management of PLL. Lipiodol as the contrast material is essential in CL because the highly viscous iodinated poppy-seed oil features not only diagnostic but also therapeutic effects. Accordingly, Lipiodolbased $\mathrm{CL}$ can be regarded as a therapeutic procedure. Position papers, interdisciplinary guidelines, and randomized controlled trials are future steps to define the ultimate value of $C L$ in the interdisciplinary management of PLL. Furthermore, the role of secondline percutaneous lymphatic interventions such as thoracic duct embolization or interstitial embolization must be specified.

\section{Conflict of Interest}

Guerbet, Villepinte, France financially supported professional language editing. The sponsor had no influence over the content of the manuscript. All authors report no conflict of interest regarding this manuscript.

\section{References}

[1] Lv S, Wang $Q$, Zhao W et al. A review of the postoperative lymphatic leakage. Oncotarget 2017; 8: 69062-69075

[2] Kim J, Won JH. Percutaneous Treatment of Chylous Ascites. Tech Vasc Interv Radiol 2016; 19: 291-298

[3] Inoue M, Nakatsuka S, Yashiro H et al. Lymphatic Intervention for Various Types of Lymphorrhea: Access and Treatment. Radiogr Rev Publ Radiol Soc N Am Inc 2016; 36: 2199-2211

[4] Tabchouri N, Frampas E, Marques F et al. Chylous Ascites Management After Pancreatic Surgery. World J Surg 2017; 41: 1054-1060

[5] McGrath EE, Blades Z, Anderson PB. Chylothorax: aetiology, diagnosis and therapeutic options. Respir Med 2010; 104: 1-8

[6] Guevara C], Rialon KL, Ramaswamy RS et al. US-Guided, Direct Puncture Retrograde Thoracic Duct Access, Lymphangiography, and Embolization: Feasibility and Efficacy. J Vasc Interv Radiol JVIR 2016; 27: 18901896

[7] Bhardwaj R, Vaziri H, Gautam A et al. Chylous Ascites: A Review of Pathogenesis, Diagnosis and Treatment. J Clin Transl Hepatol 2018; 6: 105-113

[8] Hur S, Shin JH, Lee IJ et al. Early Experience in the Management of Postoperative Lymphatic Leakage Using Lipiodol Lymphangiography and Adjunctive Glue Embolization. J Vasc Interv Radiol JVIR 2016; 27: 11771186.e1

[9] Nadolski G], Itkin M. Lymphangiography and thoracic duct embolization following unsuccessful thoracic duct ligation: Imaging findings and outcomes. J Thorac Cardiovasc Surg 2018; 156: 838-843

[10] Kortes N, Radeleff B, Sommer CM et al. Therapeutic lymphangiography and CT-guided sclerotherapy for the treatment of refractory lymphatic leakage. J Vasc Interv Radiol JVIR 2014; 25: 127-132

[11] van Goor AT, Kröger R, Klomp HM et al. Introduction of lymphangiography and percutaneous embolization of the thoracic duct in a stepwise 
approach to the management of chylous fistulas. Head Neck 2007; 29: 1017-1023

[12] Yannes M, Shin D, McCluskey K et al. Comparative Analysis of Intranodal Lymphangiography with Percutaneous Intervention for Postsurgical Chylous Effusions. J Vasc Interv Radiol JVIR 2017; 28: 704-711

[13] Schild HH, Pieper C. Chylothorax: Current Therapeutic Options. Zentralbl Chir 2019; 144: S24-S30

[14] Ginat DT, Sahler LG, Patel N et al. Post-lymphangiographic computed tomography in chylothorax after esophagogastrectomy: a case report. Lymphology 2009; 42: 130-133

[15] Alejandre-Lafont E, Krompiec C, Rau WS et al. Effectiveness of therapeutic lymphography on lymphatic leakage. Acta Radiol Stockh Swed 1987 2011; 52: 305-311

[16] Sommer CM, Goerig C, Richter GM. Intractable Postoperative Lymphatic Fistula with Impaired Wound Healing. Dtsch Arzteblatt Int 2018; 115: 376

[17] Yamamoto M, Miyata H, Yamasaki M et al. Chylothorax after esophagectomy cured by intranodal lymphangiography: a case report. Anticancer Res 2015; 35: 891-895

[18] Liberati A, Altman DG, Tetzlaff ] et al. The PRISMA statement for reporting systematic reviews and meta-analyses of studies that evaluate healthcare interventions: explanation and elaboration. BMJ 2009; 339: b2700

[19] Kos S, Haueisen H, Lachmund U et al. Lymphangiography: forgotten tool or rising star in the diagnosis and therapy of postoperative lymphatic vessel leakage. Cardiovasc Intervent Radiol 2007; 30: 968-973

[20] Gruber-Rouh T, Naguib NNN, Lehnert T et al. Direct lymphangiography as treatment option of lymphatic leakage: indications, outcomes and role in patient's management. Eur ] Radiol 2014; 83: 2167-2171

[21] Kawasaki R, Sugimoto K, Fujii M et al. Therapeutic effectiveness of diagnostic lymphangiography for refractory postoperative chylothorax and chylous ascites: correlation with radiologic findings and preceding medical treatment. Am J Roentgenol 2013; 201: 659-666

[22] Yoshimatsu R, Yamagami T, Miura $\mathrm{H}$ et al. Prediction of therapeutic effectiveness according to CT findings after therapeutic lymphangiography for lymphatic leakage. Jpn J Radiol 2013; 31: 797-802

[23] Kariya S, Nakatani M, Yoshida R et al. Repeated Intranodal Lymphangiography for the Treatment of Lymphatic Leakage. Lymphology 2015; 48: 59-63

[24] Liu J, Sato Y, Motoyama S et al. Ultrasound-guided intranodal Lipiodol lymphangiography from the groin is useful for assessment and treatment of post-esophagectomy chylothorax in three cases. Int J Surg Case Rep 2016; 29: 103-107

[25] Iwai T, Uchida J, Matsuoka Y et al. Experience of Lymphangiography as a Therapeutic Tool for Lymphatic Leakage After Kidney Transplantation. Transplant Proc 2018; 50: 2526-2530

[26] D’Hondt M, Foubert K, Penninckx F et al. Lymphangiography as a treatment method for chylous ascites following pancreaticoduodenectomy. J Gastrointest Cancer 2011; 42: 272-274

[27] Juszczyk K, Waugh R, Sandroussi C. Lymphangiography as therapeutic management of chylothorax. J Med Imaging Radiat Oncol 2013; 57 : 460-461

[28] Williams AM, Seay TM, Hundley JC et al. Direct intranodal lymphangiography for recurrent chylous ascites following liver-kidney transplantation. Liver Transplant Off Publ Am Assoc Study Liver Dis Int Liver Transplant Soc 2014; 20: 1275-1276

[29] Sheybani A, Gaba RC, Minocha J. Cerebral Embolization of Ethiodized Oil following Intranodal Lymphangiography. Semin Interv Radiol 2015; 32: $10-13$
[30] Kimura T, Hasegawa K, Morisada S et al. Lymphangiography and subsequent sclerotherapy can be easily applied by cannulation of the lymph duct with a catheter for the neonatal central vein. Clin Case Rep 2017; 5: 508-512

[31] Hirata M, Shimizu A, Abe S et al. CT-Guided Intranodal Lymphangiography for Postoperative Chylous Ascites. Cardiovasc Intervent Radiol 2017; 40: $1281-1284$

[32] Takeno A, Tamura S, Miki H et al. Chyluria after ligation of the thoracic duct: a rare complication after thoracoscopic-assisted esophagectomy for esophageal cancer. Surg Today 2014; 44: 757-760

[33] Kitahara H, Yoshitake A, Hachiya T et al. Management of Aortic Replacement-Induced Chylothorax by Lipiodol Lymphography. Ann Vasc Dis 2015; 8: 110-112

[34] Lee KH, Jung JS, Cho SB et al. Thoracic Duct Embolization with Lipiodol for Chylothorax due to Thoracic Endovascular Aortic Repair with Debranching Procedure. Korean J Thorac Cardiovasc Surg 2015; 48: 74-77

[35] Tamura T, Kubo N, Yamamoto A et al. Cervical chylous leakage following esophagectomy that was successfully treated by intranodal Lipiodol lymphangiography: a case report. BMC Surg 2017; 17: 20

[36] Jardinet T, Verbeke L, Bonne L et al. Therapeutic intranodal lymphangiography for refractory chylous ascites complicating acute necrotic pancreatitis. J Gastrointest Liver Dis JGLD 2018; 27: 195-197

[37] Hara H, Mihara M, Yamamoto M. Therapeutic lymphangiography for traumatic chylothorax. J Vasc Surg Venous Lymphat Disord 2018; 6: $237-240$

[38] Lee H, Kim S], Hur S et al. The Feasibility of Mesenteric Intranodal Lymphangiography: Its Clinical Application for Refractory Postoperative Chylous Ascites. J Vasc Interv Radiol JVIR 2018; 29: 1290-1292

[39] Nakamura K, Nakayama K, Minamoto T et al. Ultrasound-guided intranodal lymphangiography with Lipiodol for treatment of chylous ascites following surgery for ovarian cancer: A case report. Mol Clin Oncol 2018; 9: $178-180$

[40] Minegishi K, Tsubochi H, Hamamoto K et al. Massive lymphatic leakage after lung cancer surgery via median sternotomy. J Surg Case Rep 2019; 2019: rjz178

[41] Taki Y, Sato S, Suzuki K et al. A case of acute respiratory distress syndrome due to lymphography with Lipiodol for chylothorax after esophagectomy. Surg Case Rep 2019; 5: 1

[42] Yamamoto R, Mokuno Y, Matsubara H et al. Chylothorax after hepatectomy: a case report. J Med Case Reports 2018; 12: 347

[43] Vora ZA, Kandasamy D, Naranje P et al. Pediatric chylous ascites treatment with combined ultrasound and fluoroscopy-guided intranodal lymphangiography. Indian J Radiol Imaging 2019; 29: 226-228

[44] Kariya S, Nakatani M, Yoshida R et al. Repeated Intranodal Lymphangiography for the Treatment of Lymphatic LEAKAGE. Lymphology 2015; 48: 59-63

[45] Pieper CC, Hur S, Sommer CM et al. Back to the Future: Lipiodol in Lymphography-From Diagnostics to Theranostics. Invest Radiol 2019; 54: 600-615

[46] Sommer CM, Richter GM, Vollherbst DF et al. ETHIBLOC_Reloaded: First in-vivo results of the re-designed zein-based fluid embolic agent. Cogent Med 2017; 4: doi:https://doi.org/10.1080/ 2331205X.2017.1287644

[47] Chan JY, Wong EW, Ng SK et al. Conservative management of postoperative chylous fistula with octreotide and peripheral total parenteral nutrition. Ear Nose Throat ] 2017; 96: 264-267

[48] Suver DW, Perkins JA, Manning SC. Somatostatin treatment of massive lymphorrhea following excision of a lymphatic malformation. Int J Pediatr Otorhinolaryngol 2004; 68: 845-850 